\title{
A New Subfamily, Genus, and Species of Pearlfish (Teleostei: Ophidiiformes: Carapidae) from Deep Water off Indonesia
}

\author{
M. Eric Anderson ${ }^{1}$ and Fayakun Satria ${ }^{2}$ \\ ${ }^{1}$ South African Institute of Aquatic Biodiversity, \\ Private Bag 1015, Grahamstown, South Africa \\ E-mail: E.Anderson@ru.ac.za \\ ${ }^{2}$ Research Institute for Marine Fisheries, Balai Riset Perikanan Laut, \\ Jl. Muara Baru Ujung, Jakarta Utara 14444, Indonesia
}

(Received 18 August 2006; Accepted 2 March 2007)

\begin{abstract}
A new carapid fish, Tetragondacnus spilotus gen. et. sp. nov., is described from a single specimen collected off Sumatra, Indonesia. This unusual species chiefly differs from all confamilials in having the following combination of characters: dorsal fin origin in advance of anal fin origin, first neural spine a wing-like process larger than second neural spine, no rocker bone, no predorsal bone, no supraneurals, no upper jaw teeth, no developed gill rakers, parapophysis of third centrum enlarged, 13 precaudal vertebrae, 11 caudal fin rays, unmodified dorsal and anal pterygiophores, presence of scales, swim bladder simple and large, squarish mouth with two lower lip lobes, oral valve with thick median septum, united branchiostegal membranes, and large dark blotches on the body. Subfamilial status for the new species is proposed.
\end{abstract}

Key Words: Teleostei, Ophidiiformes, Carapidae, Tetragondacninae subfam. nov., Tetragondacnus spilotus gen. et sp. nov., pearlfish, Indonesia, eastern Indian Ocean.

\section{Introduction}

During 2004 and 2005 the Japan-Indonesia Deep-Sea Fisheries Resources Joint Exploration Project was instituted between Japan's Overseas Fishery Cooperation Foundation and Indonesia's Research Institute of Marine Fisheries. The purpose of the project was to collect basic oceanographic and fishery stock data for a feasibility study on developing a deep-water fishery off Java and Sumatra.

In 2005 a 107-day trawl survey aboard Indonesia's 1219-ton vessel Baruna Jaya $I V$ was conducted off Sumatra. Numerous deep-sea fishes were collected and voucher specimens were deposited at the Faculty of Fisheries, Hokkaido University, Hakodate, Japan. We studied some of these specimens during November and December, 2005, in Hakodate and discovered a single unusual ophidiiform fish taken in a bottom trawl in just over $500 \mathrm{~m}$. The specimen was identified as an ophidiiform on the basis of characters given by Cohen and Nielsen (1978) and Nielsen and Cohen (1999). The monophyly of the order has been questioned (Rosen 1985; Howes 1992), but Nielsen and Cohen (1999) listed seven characters defining Ophidiiformes and divided it into two suborders, the Ophidioidei and Bythitoidei. Our specimen does not exhibit any of the specialized characters of the viviparous 
bythitids and possesses characters that none of them have. Among the Ophidioidei it is not identifiable as a member of any of the four subfamilies of Ophidiidae and is thus placed in the family Carapidae (pearlfishes) and described herein.

Pearlfishes are a primitive family of the order Ophidiiformes currently with seven genera and 32 species (Markle and Olney 1990; Howes 1992; Markle 1999; Anderson 2005). Markle and Olney (1990) diagnosed the family on the basis of six synapomorphies, only two of which were observable in our unique specimen, with a third probable: (1) anal fin origin under vertebra 1-13 in carapids vs. 16-21 in ophidiids and bythitids (under vertebra 13 in our specimen); (2) non-autogenous scapula in carapids vs. autogenous in ophidiids and bythitids (difficult to discern in our specimen, but both the scapula and coracoid closely articulate with each other and the cleithrum, apparently in a cartilage matrix); (3) first distal pectoral radial greatly enlarged in carapids vs. not enlarged in other ophidiiforms (not discernible in our specimen); (4) supramaxilla absent in carapids vs. present in ophidiids and at least some bythitids (supramaxilla absent in our specimen); (5) enlarged hyomandibular foramen in carapids vs. small foramen in ophidiids (not discernible in our specimen); (6) larval vexillum (modified, erectile first dorsal fin element; see Govoni et al. 1984) present in carapids vs. vexillum absent in other ophidiiforms (larvae unknown in our new species). In addition, all carapids (except early larvae of some pyramodontines; D. Markle, pers. comm.) have the anal fin rays longer than the opposing dorsal fin rays, at least anteriorly (Cohen and Nielsen 1978; Markle and Olney 1990; Markle 1999), and this is the condition seen in our new species. We suggest that possession by adults of anterior anal fin rays that are longer than the opposing dorsal rays is also a carapid synapomorphy.

The pearlfishes are divided into two subfamilies, the Pyramodontinae, with two genera, and the Carapinae, with five genera (Markle and Olney 1990). The pyramodontines were diagnosed on the basis of five osteological synapomorphies, two of which are unique, and the carapines were diagnosed by 12 synapomorphies, eight of which are unique. The pyramodontines are deepwater fishes, probably benthopelagic as adults, and are easily distinguished by the dorsal fin origin being well in advance of the anal fin origin and by large fangs in both jaws. The carapines, with the exception of Echiodon (12 species), are inshore, mostly tropical fishes, and are distinguished by the dorsal fin origin being behind the anal fin origin and by usually having only small teeth (see also Parmentier et al. 2000), although fangs are present in Echiodon and Onuxodon.

The pearlfish described here has the dorsal fin origin well in advance of the anal fin origin as in pyramodontines. Unlike members of that subfamily, as diagnosed by Markle and Olney (1990), it has no fang-like teeth and differs in a few important osteological characters. Unlike carapines it possesses pleural ribs, has long (plesiomorphic) dorsal and anal fin pterygiophores, 13 vertebrae anterior to the anal fin origin (one to nine in carapines), and a long pectoral fin. In addition, the new pearlfish has a unique, squarish mouth structure with no upper jaw teeth, the lower jaw with two lip lobes, cycloid scales, united branchiostegal membranes, no developed gill rakers, a large swim bladder with an anterior expansion, and a confusing array of primitive and derived osteological characters. We believe the species not only represents a new genus of pearlfish but also a third subfamily. 


\section{Materials and Methods}

Measurements were made with electronic calipers or an ocular micrometer to the nearest $0.1 \mathrm{~mm}$. Counts of skeletal features, osteological observations, and camera lucida drawings were made mostly from radiographs. Dissection of both shoulder girdles to reveal characters of the anterior vertebral column, together with the hunched condition of the preserved specimen resulted in distortion of some features, and these were reconstructed. The systematic protocol follows that established for pearlfishes by Markle et al. (1983) and Markle and Olney (1990). For ease of comparison, their abbreviations for meristic characters are repeated here: $A_{30}$, number of anal fin rays anterior to a vertical through the articulation between vertebrae 30 and 31; ARDO, anal fin rays anterior to the dorsal fin origin; $\mathrm{D}_{30}$, dorsal fin rays anterior to a vertical through the articulation of vertebrae 30 and 31; DRAO, dorsal fin rays anterior to the anal fin origin; $\mathrm{P}_{1}$, pectoral fin rays; $\mathrm{PCV}$, precaudal vertebrae; VAO, number of vertebrae to the anal fin origin; VDO, vertebrae to the dorsal fin origin. The abbreviation HUMZ refers to the Graduate School of Fisheries Sciences, Hokkaido University, Hakodate, Japan, and SAIAB to the South African Institute of Aquatic Biodiversity (formerly RUSI). Other abbreviations are found in the figure captions.

Comparative material examined. Carapinae. Carapus mourlani (Petit, 1934): SAIAB 8843 (1 specimen; $119 \mathrm{~mm}$ total length [TL]), Sodwana Bay, South Africa. Echiodon atopus Anderson, 2005: USNM 380406 (holotype; $176 \mathrm{~mm}$ TL), Tristan da Cunha Group. Encheliophis boraborensis (Kaup, 1856): SAIAB 44312 (4 specimens; 53-250 mm TL), Bassas da India, Mozambique Channel. Encheliophis homei (Richardson, 1846): SAIAB 44310 (4 specimens; 110-142 mm TL), Bassas da India, Mozambique Channel. Eurypleuron owasianum (Matsubara, 1953) (holotype of Carapus cinereus Smith, 1955): SAIAB 309 (215 mm TL), Inhaca Island, Mozambique. Onuxodon parvibrachium (Fowler, 1927): SAIAB 14832 (4 specimens; 85-98 mm TL), Praslin Island, Seychelles.

Pyramodontinae. Pyramodon punctatus (Regan, 1914): SAIAB 4814 (1 specimen; $242 \mathrm{~mm}$ TL), off East London, South Africa. Pyramodon ventralis Smith and Radcliffe, 1913: SAIAB 13769 (1 specimen; $227 \mathrm{~mm}$ TL), off Sumatra, Indonesia. Snyderidia canina Gilbert, 1905: SAIAB 77528 (1 specimen; $346 \mathrm{~mm}$ TL), off Surinam.

\section{Systematics}

Tetragondacninae subfam. nov.

Type genus. Tetragondacnus gen. nov.

Diagnosis. Dorsal fin origin well in advance of anal fin origin; first neural spine a wing-like process, larger than second spine; ethmoid not rounded in lateral view; no rocker bone; no predorsal bone; no ventral facet on third vertebral centrum for attachment of retractor dorsalis muscle; parapophysis of third centrum enlarged; 13 precaudal vertebrae; haemal spines of caudal vertebrae not spatulate; pleural ribs present; no supraneurals; dorsal and anal pterygiophores long, unmodified; 11 caudal fin rays; pectoral fin long; pelvic bone present, fin rays absent; swim bladder filling entire coelom, not divided into anterior and posterior sec- 
tions, without tunic ridge, anterior end laterally expanded; lips thickened, lower jaw with horizontal and lateral lip lobes; mouth opening squarish when jaws protruded; no teeth in upper jaw, vomer, or palatines; teeth in lower jaw small, lanceolate (no fangs); teeth present on third basibranchial bone; oral valve with thickened medial septum; branchiostegal membranes united, free of isthmus posteriorly; scales present; seven branchiostegal rays; opercular spine strong, rounded in cross-section; no developed gill rakers.

Tetragondacnus gen. nov.

Type species. Tetragondacnus spilotus sp. nov.

Diagnosis. As for subfamily.

Etymology. From the Greek tetragonos (square) and dakno (to bite), alluding to the squarish shape of the open mouth. Gender masculine.

\section{Tetragondacnus spilotus sp. nov.}

(Figs 1-5)

Material examined. Holotype: HUMZ 194618 (male, $165 \mathrm{~mm}$ total length), off $\mathrm{NW}$ Sumatra, Indonesia, $03^{\circ} 18.3^{\prime} \mathrm{N}, 95^{\circ} 03.1^{\prime} \mathrm{E}$ to $03^{\circ} 16.7^{\prime} \mathrm{N}, 95^{\circ} 05.2^{\prime} \mathrm{E}$, Baruna Jaya $I V$, stn 119, 518-528 m, 31 July 2005.

Diagnosis. Vertebrae $13+64=77$; pectoral fin rays 24 ; gill rakers $5+7$, minute nubs or pads; pseudobranch filaments $6 ; \mathrm{D}_{30} 69 ; \mathrm{A}_{30} 45$; ARDO 0; DRAO 27; VAO 13; VDO 5. Head pores (Fig. 2): IO 3; SO 1; LT 1; MD 3; POP 0; ST 0.

Description. Proportions as percent head length: body depth 66.4; bony interorbital width 10.8; eye diameter 28.3; head depth 57.0; head width 39.9 ; lower jaw length 44.0; upper jaw length 36.8 ; length to pectoral base 114.4; preanal length

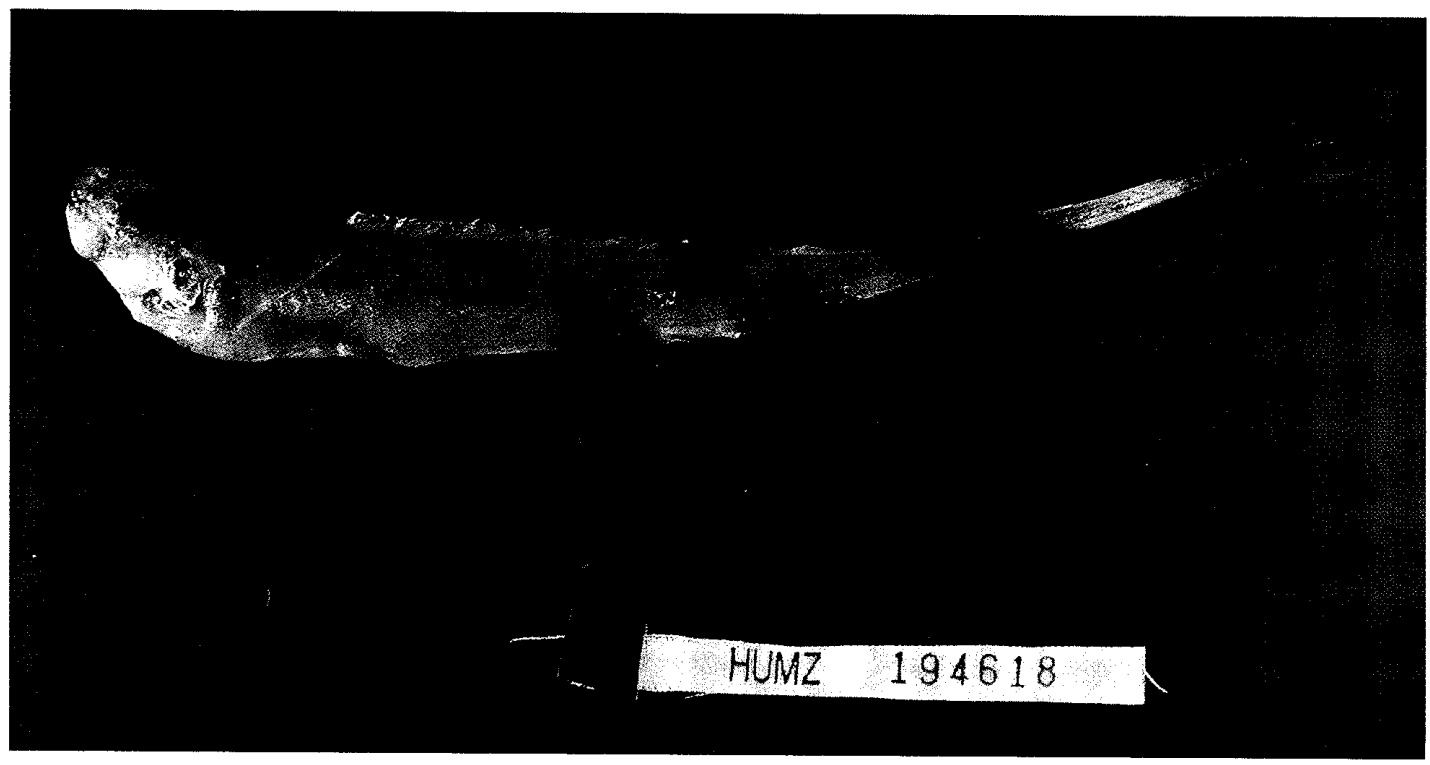

Fig. 1. Tetragondacnus spilotus gen. et sp. nov., holotype (HUMZ 194618), $165 \mathrm{~mm}$ TL, off Sumatra, Indonesia. Photo by HUMZ personnel. 

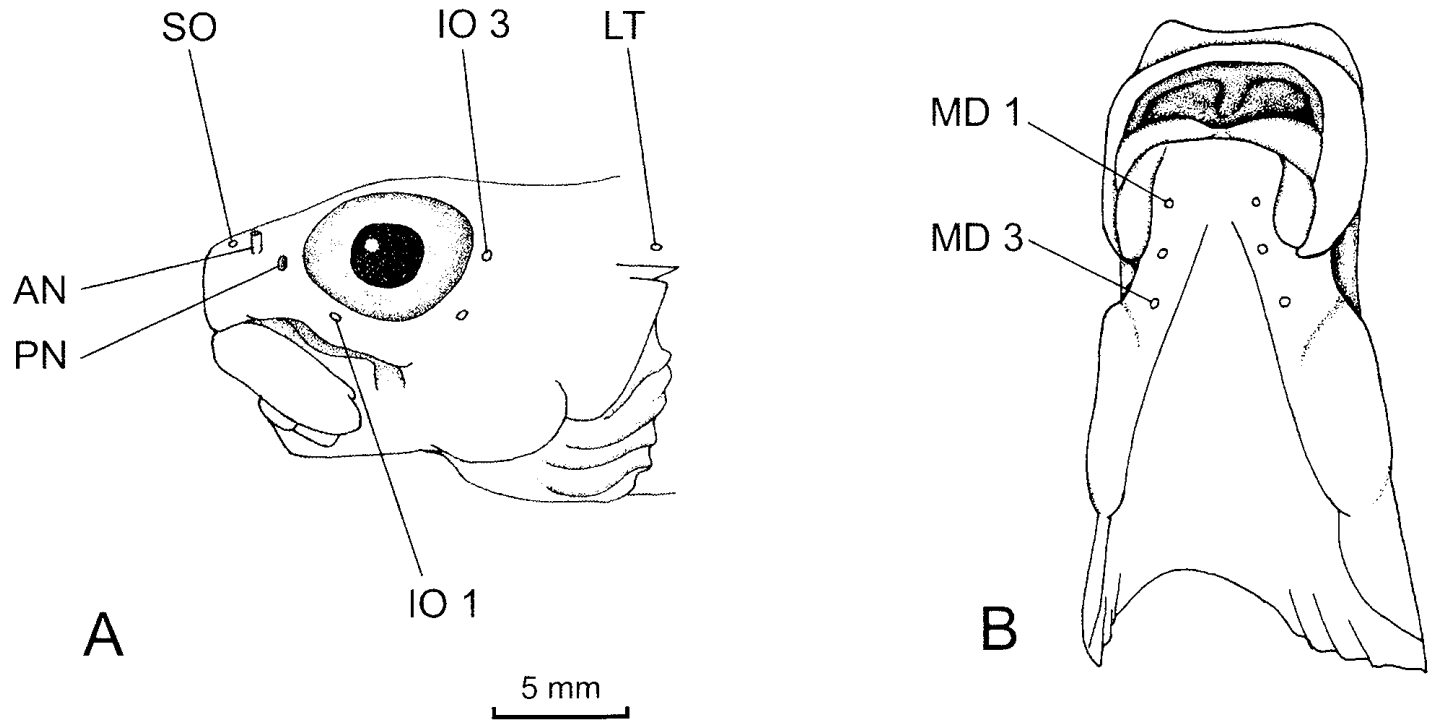

Fig. 2. Cephalic lateralis pores of holotype of Tetragondacnus spilotus gen. et sp. nov. A, Left lateral view; B, ventral view. Abbreviations: AN, anterior nostril; IO, infraorbital pore; LT, lateral-temporal pore; MD, mandibular pore; $\mathrm{PN}$, posterior nostril; SO, supraorbital pore.

188.8; predorsal length 112.6; pectoral fin length 57.9; snout length 25.6; distance snout to anus 172.7 .

Head ovoid, snout steeply sloping in front of eye to subterminal mouth, producing weak rostrum. Eye large, circular, entering dorsal profile of head. Preopercle greatly expanded posteroventrally, making cheek somewhat elliptical. Cephalic lateralis pores small, rounded; three infraorbitals and mandibulars, a single lateral-temporal and supraorbital present; preopercular and supratemporal pores absent (Fig. 2). Body lateral line of superficial neuromasts, originating just behind lateral-temporal pore, extending to near tail tip just beneath dorsal fin base. No sensory papillae on head or body.

Mouth subterminal, lips greatly thickened, with anterior portion of upper jaw directed laterally, posterior portion directed posteriorly, forming squarish opening when mouth fully protruded. Maxilla closely articulating with premaxilla. No supramaxilla. Upper jaw extending posteriorly to middle of eye and set in deep groove running entire jaw length. Lower jaw with two fleshy lip lobes: anteriormost horizontal, forming lower part of squared-off mouth; posteriormost originating under anterior lobe and extending to corner of jaw (Fig. 2). No teeth in upper jaw, vomer, and palatines. Lower jaw teeth minute, recurved, lanceolate, in three rows in horizontal (anterior) portion of jaw only; no fang-like or cardiform teeth. Teeth present on third basibranchial bone. Oral valve well developed, with thick, fleshy medial septum.

Gill opening large, branchiostegal membranes united and free of isthmus posteriorly; membranes joined slightly anterior to vertical through posterior margin of preopercle. Upper end of gill opening with weak, squared-off opercular flap. Gill rakers of first arch $5+7$, greatly reduced; innermost three of upper limb mere pads with small denticles, outer two triangular nubs without denticles, as also on all seven lower rakers. 


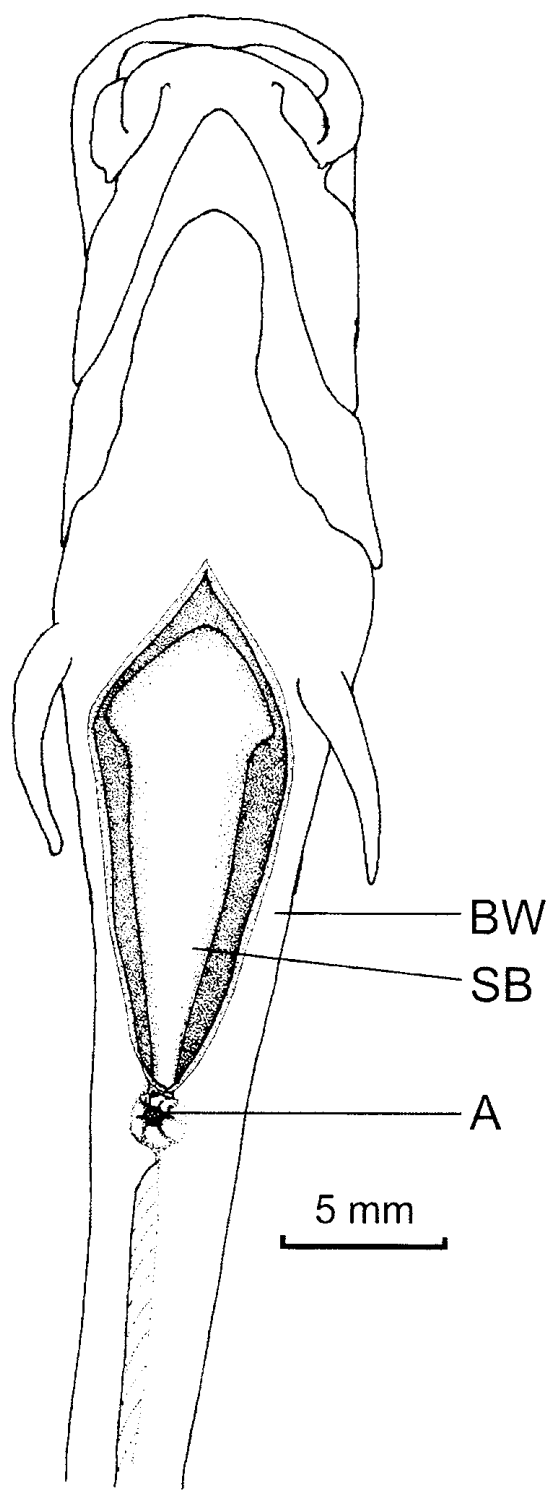

Fig. 3. Swim bladder of holotype of Tetragondacnus spilotus gen. et sp. nov. in ventral view. Abbreviations: A, anus; BW, body wall; SB, swim bladder.

Scales cycloid, non-imbricate, on pectoral base, body, and tail but not on fins. Scales on head covering nape, anterior portion of cheek, suborbit, interorbit, and snout laterally but not medially. No scales on jaws, opercle, or branchiostegal membranes.

Dorsal fin origin slightly posterior to vertical through pectoral fin origin, rays shorter than opposing anal fin rays. Anal fin origin behind posterior margin of appressed pectoral fin. Pectoral fin origin slightly below body midline, insertion on abdomen. Caudal fin confluent with dorsal and anal fins, slightly longer than eye.

Swim bladder filling entire coelom, its posterior end nesting in small concavity just above anus. Bladder simple, without constrictions, but laterally expanded anteriorly (Fig. 3). No tunic ridges or posterior terminal bulb.

Details of shoulder girdle not clear from radiographs. Cleithrum relatively 


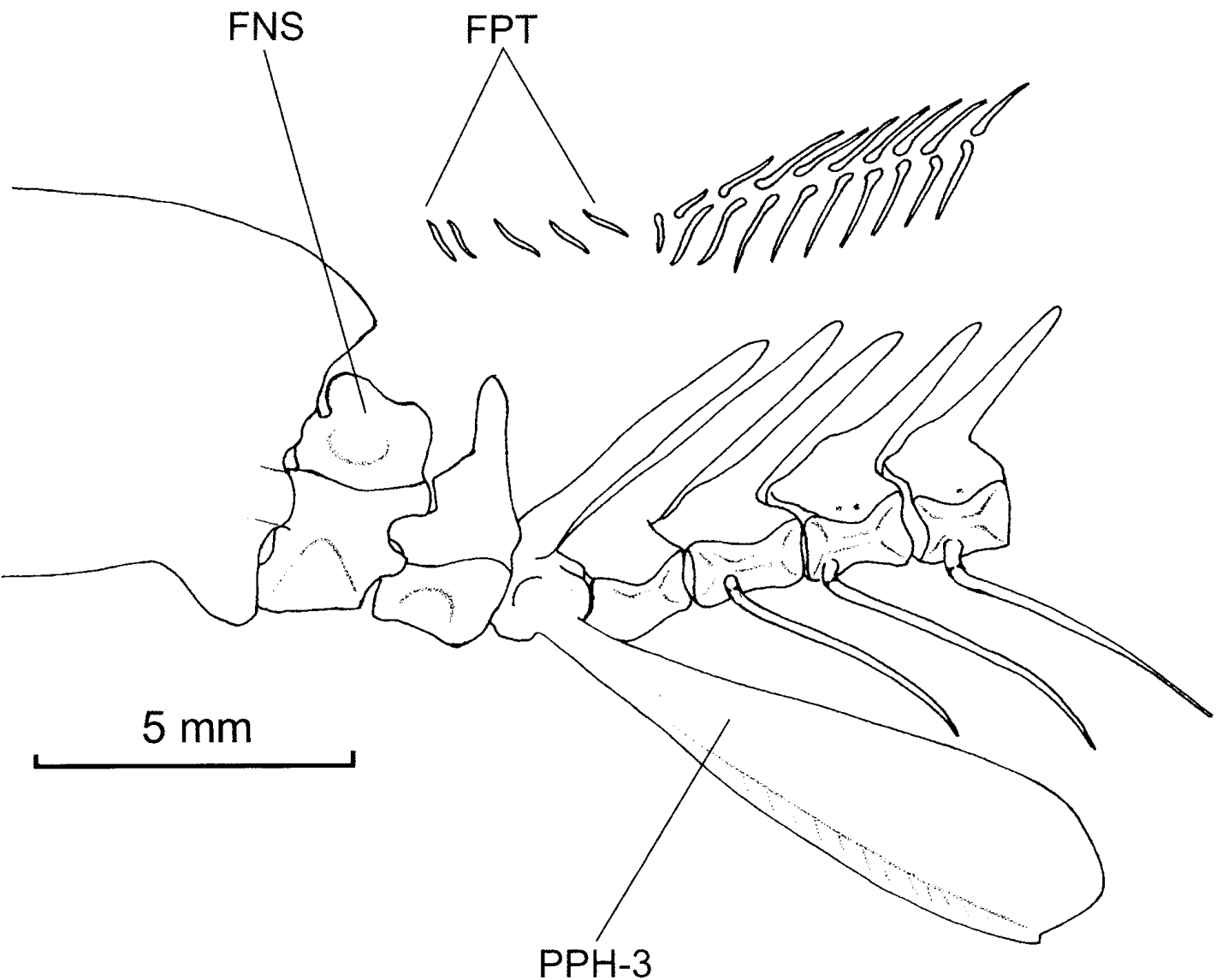

Fig. 4. Diagram of left view of rear of cranium, anterior vertebrae, and anterior portion of dorsal fin of holotype of Tetragondacnus spilotus gen. et sp. nov. Third through seventh vertebrae repositioned from preserved condition (with dorsum hunched). Position and shape of parapophysis of third centrum reconstructed from specimen (altered during dissection). Right pleural ribs not shown. Camera lucida drawing from radiographs. Abbreviations: FNS, first neural spine; FPT, free dorsal pterygiophores; PPH-3, parapophysis of third centrum.

straight. Supracleithrum short, narrow, and sharply pointed at posterior end. Four actinosts. Shapes of scapula and coracoid just discernible, scapula appearing non-autogenous, closely articulating with coracoid and cleithrum in cartilaginous matrix; lower end of coracoid with apparently ossified ventral arm. No postcleithrum. Posttemporal V-shaped.

Osteological observations of cranium and vertebral column from radiographs (Figs 4, 5). Ethmoid angular, gently sloping dorsally, steeply sloping ventrally and somewhat thickened there. Lateral ethmoid plate-like. Exoccipital processes weak, a dorsal one articulating with wing-like first neural spine (this being more massive than second neural spine) and a ventral one articulating with a dorsal facet of first vertebral centrum. First neural spine similar to that shown by Rose (1961, fig. 2) for Ophidion holbrookii Putnam, 1874, but with a shallow concavity. Anterior facets of first centrum difficult to discern, but ventral facet not concave, contacting basioccipital along flat, vertical articulation. Third centrum with expanded parapophysis, under which fits the anterior bulge of swim bladder; third centrum with- 


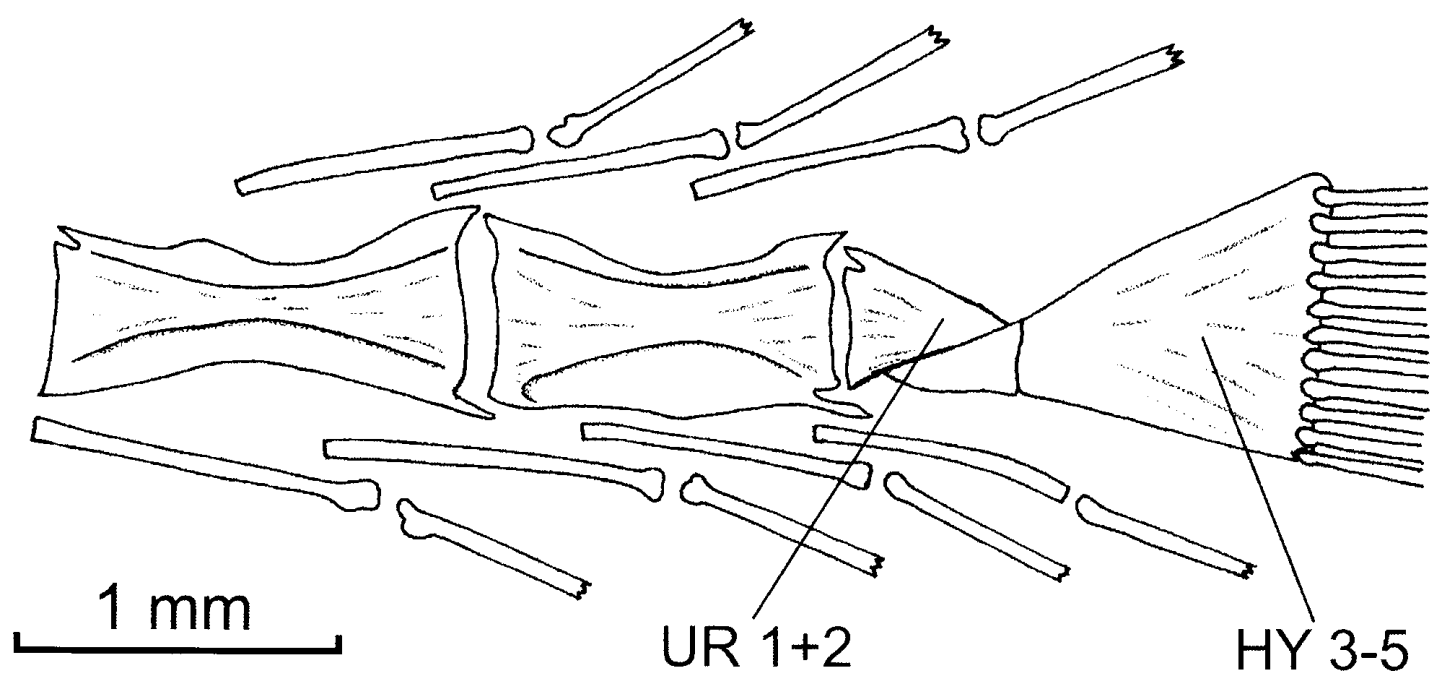

Fig. 5. Caudal skeleton of holotype of Tetragondacnus spilotus gen. et sp. nov. Camera lucida drawing from radiographs. Abbreviations: HY 3-5, fused third through fifth hypurals; UR $1+2$, first and second ural centra.

out expanded facet for insertion of retractor dorsalis muscle; its neural spine simple, with weak anterior spur. Pleural ribs present, commencing on fifth centrum. Haemal spines of caudal vertebrae normal, not spatulate. Five small, rayless pterygiophores anterior to first dorsal fin ray. No supraneural cartilages, rocker bone, or predorsal bone. Dorsal and anal fin pterygiophores normal struts, not frail or shortened and inclined anteriad. Caudal skeleton (Fig. 5) with hypurals fused, no parhypural. Ural centra 1 and 2 closely articulating but not fused. No uroneural or epurals. Fin with 11 rays. Preural centra without neural or haemal spines.

Fresh coloration. Body and top of head gray, with small, scattered melanophores. Ventral surface of head including lips off-white. Body and tail with six irregular black blotches, posteriormost five of which extending onto fins; melanophore density between blotches less than on body more anteriorly. Fins translucent between blotches and anterior to them. Eyes blue. Peritoneum and lining of orobranchial chamber pale. Swim bladder white, with small, scattered melanophores

Etymology. From the Greek spilotos (spotted, stained), alluding to the color pattern of the new species.

Remarks. Observable anatomical features in the single specimen of Tetragondacnus spilotus show a mosaic of plesiomorphic and autapomorphic characters. Following Markle and Olney (1990), we exclude it from the subfamily Carapinae on the basis of different states of three unique synapomorphies of that clade: (1) the presence of pleural ribs in Tetragondacnus vs. their absence in carapines; (2) unmodified pterygiophores in Tetragondacnus vs. short, anteriorly-directed dorsal and anal pterygiophores in carapines; and (3) 24 pectoral fin rays in Tetragondacnus vs. less than 21 rays in carapines. In addition, the dorsal fin origin is well in advance of the anal fin origin in Tetragondacnus vs. the reverse in carapines except adults of Onuxodon in which the fin origins are opposite one another or nearly so. Characters that exclude Tetragondacnus from the Pyramodontinae include: (1) no facet on the third vertebral centrum for the retractor dorsalis muscle; 
(2) ethmoid bone not rounded but with a pronounced bump; and (3) no fang-like teeth.

Six autapomorphies exist in Tetragondacnus that, in addition to the exclusionary characters noted above in all other carapid genera, require the erection of a new subfamily of pearlfish: (1) the squarish mouth structure with a curved upper jaw; (2) thickened lips, with the lower lip bilobed; (3) the lack of upper jaw teeth; (4) the unusual structure of the first neural spine; (5) the lack of developed gill rakers, all being greatly reduced (also true for most species of Encheliophis); and (6) the oral valve with a thickened medial septum.

Despite these unique and derived character states, Tetragondacnus spilotus exhibits many plesiomorphic states. Important among these are: (1) the dorsal fin origin in advance of the anal fin origin; (2) no predorsal bone (secondarily lost in Carapini); (3) the retention of pleural ribs; (4) the retention of scales; (5) a PCV count of 13; (6) 11 caudal fin rays; (7) unmodified dorsal and anal fin pterygiophores; (8) a large, unmodified swim bladder filling the entire coelom; and (9) no rocker bone.

A few homoplastic apomorphic states occur in Tetragondacnus and other carapids (Markle and Olney 1990; Anderson 2005). These include: (1) united branchiostegal membranes (shared with five species of Carapini (sensu Parmentier et al. 2000)); (2) a long pectoral fin (shared with pyramodontines and two species of Echiodon, although the fin is not quite as long relative to the head in Tetragondacnus); and (3) the loss of pelvic fins (retained in Pyramodon).

\section{Acknowledgements}

We thank Drs Kazuhiro Nakaya, Mamoru Yabe, and Hisashi Imamura, Hokkaido University, for space and curatorial needs during our visits in 2005. Indonesian and Japanese scientists and technical support staff, too numerous to mention here, include personnel at the Research Institute for Marine Fisheries (RIMF-BRPL), Research Center for Capture Fisheries (RCCF-PRPT), Agency of Marine and Fisheries Research (AMFR-BRKP), Agency for the Assessment and Application of Technology (BPPT), and Japan's Overseas Fishery Cooperation Foundation (OFCF). Operation of Baruna Jaya IV was conducted by the RIMF and OFCF. Elaine Heemstra rendered the illustrations.

\section{References}

Anderson, M. E. 2005. Description of a new species of Echiodon (Teleostei: Carapidae) from the South Atlantic. Zootaxa 809: 1-5.

Cohen, D. M. and Nielsen, J. G. 1978. Guide to the identification of genera of the fish order Ophidiiformes with a tentative classification of the order. NOAA Technical Report NMFS Circular 417: 1-72.

Govoni, J. J., Olney, J. E., Markle, D. F. and Curtsinger, W. R. 1984. Observations on structure and evaluation of possible functions of the vexillum in larval Carapidae (Ophidiiformes). Bulletin of Marine Science 34: 60-70.

Howes, G. J. 1992. Notes on the anatomy and classification of ophidifform fishes with particu- 
lar reference to the abyssal genus Acanthonus Günther, 1878. Bulletin of the British Museum of Natural History (Zoology) 58: 95-131.

Markle, D. F. 1999. Family Carapidae. Pp. 10-21. In: Nielsen, J. G., Cohen, D. M., Markle, D. F. and Robins, C. R. (Eds) FAO Species Catalogue, Volume 18, Ophidiiform Fishes of the World. Order Ophidiiformes. FAO, Rome.

Markle, D. F. and Olney, J. E. 1990. Systematics of the pearlfishes (Pisces: Carapidae). Bulletin of Marine Science 47: 269-410.

Markle, D. F., Williams, J. T. and Olney, J. E. 1983. Description of a new species of Echiodon (Teleostei: Carapidae) from Antarctic and adjacent seas. Proceedings of the Biological Society of Washington 96: 645-657.

Nielsen, J. G. and Cohen, D. M. 1999. Introduction. Pp. 1-8. In: Nielsen, J. G., Cohen, D. M., Markle, D. F. and Robins, C. R. (Eds) FAO Species Catalogue, Volume 18, Ophidiiform Fishes of the World. Order Ophidiiformes. FAO, Rome.

Parmentier, E., Castillo, G., Chardon, M. and Vandewalle, P. 2000. Phylogenetic analysis of the pearlfish tribe Carapini (Pisces: Carapidae). Acta Zoologica 81: 293-306.

Rose, J. A. 1961. Anatomy and sexual dimorphism of the swim bladder and vertebral column in Ophidion holbrooki (Pisces: Ophidiidae). Bulletin of Marine Science of the Gulf and Caribbean 11: 280-308.

Rosen, D. E. 1985. An essay on euteleostean classification. American Museum Novitates 2827: $1-57$. 